\title{
Communications in the IPCC's Sixth Assessment Report cycle
}

\author{
Jonathan Lynn ${ }^{1}$ (D) Nina Peeva ${ }^{1}$
}

Received: 14 January 2021 / Accepted: 24 September 2021/Published online: 30 November 2021 (c) The Author(s), under exclusive licence to Springer Nature B.V. 2021

\begin{abstract}
The Intergovernmental Panel on Climate Change (IPCC) has been renewing its communications activities in the current assessment cycle, building on the innovations that underpinned the Fifth Assessment Report. An Expert Meeting on Communication in Oslo in 2016 sought to compile and discuss the lessons learnt during Fifth Assessment Report and inform the Communications Strategies for the Sixth Assessment Report (The overall Communications Strategy is adopted by the IPCC. Individual communications strategies for the various reports are signed off by the Chair and respective Co-Chairs.) This article describes the progress made, in the context of the IPCC's communications goals and specific challenges. Developments in the current cycle include a more systematic approach to developing key statements to communicate the findings of the reports. The IPCC has expanded the number and geographic range of its outreach activities, targeting interested stakeholders beyond the core audience of policymakers. Communications work was strengthened by reinforcing the Working Group Technical Support Units, which support the author teams, with communications specialists. The first product in this cycle, the 2018 Special Report on Global Warming of $1.5^{\circ} \mathrm{C}$, was by some measures the most influential report on climate change to date. It attracted enormous media coverage, transforming and galvanizing public interest in global warming. With the two subsequent special reports in 2019 on land and the ocean and cryosphere, this has focused attention and scrutiny on the IPCC. The latest report, Climate Change 2021: The Physical Science Basis, was released in August 2021 and broke all records for coverage of an IPCC report. This makes effective communication all the more important, for the remainder of the current cycle due for completion in 2022 and beyond.
\end{abstract}

Keywords Climate change $\cdot$ Science $\cdot$ Communications $\cdot$ Outreach $\cdot$ Messaging $\cdot$ Policyrelevance IPCC

This article was mainly prepared before the release of the Working Group I contribution to the Sixth Assessment Report (Climate Change 2021: The Physical Science Basis) in August 2021.

The authors are writing in a personal capacity.

Jonathan Lynn

jlynn@wmo.int

1 IPCC, Geneva, Switzerland 
In its three-decade history, the Intergovernmental Panel on Climate Change (IPCC) has completed five full assessment cycles. The current one, the Sixth Assessment Report cycle, is the most ambitious in terms of the number of reports and the cross-working group approach. Since the beginning of this cycle, the IPCC has released three Special Reports and a refinement to its latest Methodology Report on estimating greenhouse gas inventories. The Working Group I contribution to the Sixth Assessment Report (Climate Change 2021: The Physical Science Basis) was released at a press conference on 9 August 2021 and broke all records for coverage of an IPCC report. The remaining components of the Sixth Assessment Report will be finalized and released in 2022 (see Fig. 1). ${ }^{1}$

We often hear that the reports of the IPCC are the gold standard of climate science. Hundreds of distinguished scientists assess thousands of scientific papers, carefully draft their conclusions and the associated confidence levels, taking into consideration tens of thousands of review comments provided by hundreds of other scientists and experts: all part of the process to inform policymakers at all levels on what we know about climate change.

"But let me pose a brutal question," IPCC Chair Hoesung Lee once asked. "What use are IPCC reports if many of the intended users cannot understand them, do not know where to find what they need, or cannot use them in their own work?"

The IPCC has been working for many years to improve its communications to its main audience of policymakers, as well as to the general public and stakeholders who seek reliable and up-to-date information about climate change. During the previous fifth assessment cycle, the IPCC brought its communications activities in line with normal practice by introducing press releases, providing materials to the media under embargo, live-streaming press conferences, implementing strategies for handling leaks, distilling key findings into headline statements, greatly expanding the number of media interviews at report releases, and developing a dedicated outreach programme. By one measure, the communication of Fifth Assessment Report was outstandingly successful: it provided the scientific input to the UN Climate Conference COP21 in 2015, and thus the scientific foundation for the Paris Agreement.

But the IPCC understands that it needs to continue efforts to communicate more effectively to its users. With that commitment come various challenges and opportunities. Some are common to any organization communicating science to non-specialists. For instance, the IPCC's work spans the full spectrum of disciplines - from the physical sciences to the life and social sciences, and beyond. Simplifying complex findings for communication purposes risks sacrificing precision. Other communications constraints arise from the unique role and strengths of the IPCC (e.g., the need to be policy-relevant but not policy-prescriptive) and the IPCC's processes (e.g., formal line-by-line approval by policymakers). Much of what follows below reflects how the IPCC is addressing these challenges, and more, in the Sixth Assessment Report cycle.

\section{The IPCC's evolving Communications Strategy: goals and challenges}

The IPCC Communications Strategy agreed in 2012 sets out two main goals:

1 As of May 2021. 
- To communicate its assessment findings and methodologies, by providing clear and balanced information on climate change, including scientific uncertainties, without compromising accuracy;

- To explain the way the IPCC works, selects its authors and reviewers, and produces its reports and other products. This will promote the understanding of the reports and underpin its reputation as a credible, transparent, balanced, and authoritative scientific body.

The Communications Strategy sets out a protocol for providing rapid responses in situations where the IPCC's credibility or integrity is challenged. Since the introduction of the strategy, such situations have not arisen. However, the process has been used to address leaks of confidential drafts of IPCC reports. The official position of the IPCC is ultimately the approved, adopted, and accepted reports. Thus, it is not possible for the IPCC to engage in substantive dialogue about scientific content on social media that has not gone through the formal IPCC process.

To take stock of the progress in the Fifth Assessment Report with respect to communication, the IPCC held an Expert Meeting on Communication in Oslo in February 2016. The meeting provided an opportunity to share experiences, best practices, and lessons learned in the fifth assessment cycle, and resulted in a series of recommendations for the Sixth Assessment Report. The Panel addressed some of the key recommendations from the Expert Meeting in a Decision on Communications for the Sixth Assessment Report (see Decision IPCC/XLIII-10 on page 19) taken at the 43rd Session of the Panel in April 2016. The decision called inter alia for more accessible language in the Summary for Policymakers, the involvement of communications specialists in the writing process, and the possibility of including communications specialists in the Technical Support Units to work closely with the authors of the reports and the relevant Bureaux.

All this had implications for the way the IPCC works. The IPCC manages communications activities with a tiny staff. The number of communications specialists in the IPCC Secretariat, the only entity that provides continuity between the cycles, rose to three from one during the previous fifth assessment cycle. A fourth specialist has recently been employed on a temporary basis. The Secretariat communications team can and does reinforce its numbers at times of peak activity, such as report releases, by taking on consultants, often seconded by other bodies. Such arrangements are governed by the IPCC Communications Strategy to ensure the integrity, objectivity, and transparency of the IPCC are secure. Following the Decision mentioned above, all three Working Groups have taken on communications specialists in their Technical Support Units (see "Sect. 2," below).

The pressure to make the reports more accessible comes from policymakers as well as media, communications professionals, and the general public. After the Fifth Assessment Report, some senior policymakers called for a "Summary for Citizens" to complement the Summary for Policymakers. The challenge here is that IPCC reports go through a formal process of review, after which the IPCC's 195 member governments approve the Summary for Policymakers and accept the full report. This rigorous process by the ultimate users of the report, in dialogue with those who have prepared it, is one of the strengths of the IPCC assessment. This means the report texts cannot be changed. Formal IPCC communications materials that paraphrase the report text, rather than quote it directly, may attract criticism from governments as well as from scientists who fear that scientific rigour may be lost. This makes it challenging for the IPCC to present the reports to non-specialists in more accessible language. 
There are a number of other specific challenges that the IPCC contends with, in addition to the accessibility of approved language. As an intergovernmental organization, the IPCC must pay particular attention to balance in the way it presents its findings, for instance in geographical or sectoral coverage. This imposes a strict discipline on how it communicates. An example of this was that up to the 2007 Fourth Assessment Report, for which the IPCC was awarded the Nobel Peace Prize, the IPCC did not issue its own press releases to present the reports. Some governments would have seen it as improper for the organization to highlight some findings over others in a media document that aims to summarize a report.

Being policy-relevant without being policy-prescriptive, the IPCC does not campaign or advocate. This neutrality reinforces the IPCC's credibility that is derived from the IPCC's processes, but can give rise to criticism that the IPCC is not communicating with sufficient urgency or clarity.

\section{Communications innovations in the sixth assessment cycle}

Since the Expert Meeting on Communications in Oslo in 2019, the IPCC has improved its communications work further with a scaled-up and more sophisticated outreach programme, greater media engagement, scientifically rigorous yet accessible videos, a userfriendly website, and greater use of digital technology and social media. The IPCC Communication Strategy is kept under review and is currently being examined with a view to monitoring geographical balance and measuring impact, among other things.

While the primary users of IPCC reports have been policymakers, the diversity and number of stakeholders interested in the work of the IPCC have been increasing rapidly: citizens, civil society, educators, business, and subnational policymakers including urban decision-makers, students, and children. The IPCC has undertaken an unprecedented outreach effort working with its member countries, observers, and partners to implement activities tailored to the needs of these various audiences around the world. While IPCC reports are prepared for all policymakers worldwide, there is a growing understanding that outreach and communications materials should be tailored to the region and audience addressed, in so far as the IPCC's capacity allows. The enhanced regional content of the Sixth Assessment Report will be reflected in dedicated regional outreach materials. For example, IPCC Vice-Chair Youba Sokona and Working Group II Co-Chair Debra Roberts have provided leadership for the development of communications materials targeting various regional audiences but consistent with the approved texts. Working Group II ViceChair Joy Pereira has run workshops with young scientists on reviewing IPCC drafts.

Another major priority in the Sixth Assessment Report cycle has been how to embed communications into the development of the report from the start rather than attempting to bolt it on once the reports have been finalized. The communications specialists in the Working Group Technical Support Units in this cycle are exploring ways to work more closely with IPCC authors to ensure a consistent and "upstream" consideration of communication issues when drafting the chapters and Summary for Policymakers, for example.

The newly expanded IPCC communications team has worked, in turn, with external communications experts to bring evidence-based guidance to the authors. For instance, the Technical Support Unit of IPCC Working Group I (the physical science basis of climate change) commissioned a Handbook for IPCC authors on effective public engagement by Climate Outreach, who subsequently compiled a series of case studies showing these principles in action by IPCC Working Group I authors around the world. The Technical 
Support Units have also worked with communications experts at USC Dornsife on usertesting of eight key pieces of terminology in the reports. This found that many commonly used terms in IPCC and general climate science discourse, including some not perceived as jargon by authors (or communications specialists), were not well understood by a sampling of the American public. In some cases, they were understood outside a climate change context, for instance "sustainable development" was seen as something to do with real estate, and "adaptation" as related to adapting books into cinema. For full details, see separate article in this Special Issue (de Bruin et al.). And the Technical Support Units have initiated work on communicating with policymakers.

The sixth assessment cycle has also seen a more systematic approach to the messaging ${ }^{2}$ of the reports. Already in the fifth assessment cycle, headline statements were introduced for the Working Group I and Synthesis Reports to provide a concise narrative of the key findings in the Summary for Policymakers. This innovation was welcomed enthusiastically by policymakers. But many non-specialists found the language of some headline statements was still obscure and therefore sub-optimal as a communications tool, a view also expressed at the Oslo meeting. The next advance came from an unexpected quarter. As had been done for Fifth Assessment Report, the IPCC provided training for the authors of the Special Report on Global Warming of $1.5^{\circ} \mathrm{C}$ (SR15), to give them confidence in handling media interviews and to focus them on the key messages they might want to deliver during a short media interaction. Thus, the media training encourages the authors to think how they would express the scientific findings in their own words. The iterative media training process yielded considerable agreement on these formulations among authors. With further work, key messages emerged developed by the authors and the relevant Bureau that could underpin not only interviews but also other communications activities such as presentations of the reports. This media training approach has been intensified for the subsequent sixth cycle special reports and main assessment to develop rigorous and consistent bottomup messaging by the authors of the report.

Thus, authors and Bureau members came up with a simple but powerful summary of the report:

- Every half a degree matters

- Every year matters

- Every choice matters

Such text, used for example in the press conference to release a report, can perhaps be considered as a "Summary for Citizens" developed by the IPCC scientists, even if it has not gone through the full IPCC review and approval process. And it enables the IPCC to summarize its findings to non-specialist audiences on a range of media.

The IPCC has also reviewed its approach to data visualizations from a communications perspective. As Working Group III Co-Chair Jim Skea has observed: "A picture is worth a thousand words, but sometimes you need a thousand words to explain an IPCC figure." There is a growing awareness that the figures that go into the summary for policymakers and are directed at a broad range of audiences may need to be more accessible than those

\footnotetext{
${ }^{2}$ Some IPCC authors and Technical Support Units staff argue that "messaging" could be understood as a value-laden term that is not consistent with the IPCC's non-prescriptive approach. The term is used by the communications team to mean the essential information that a journalist or audience would take away from an interview or presentation.
} 


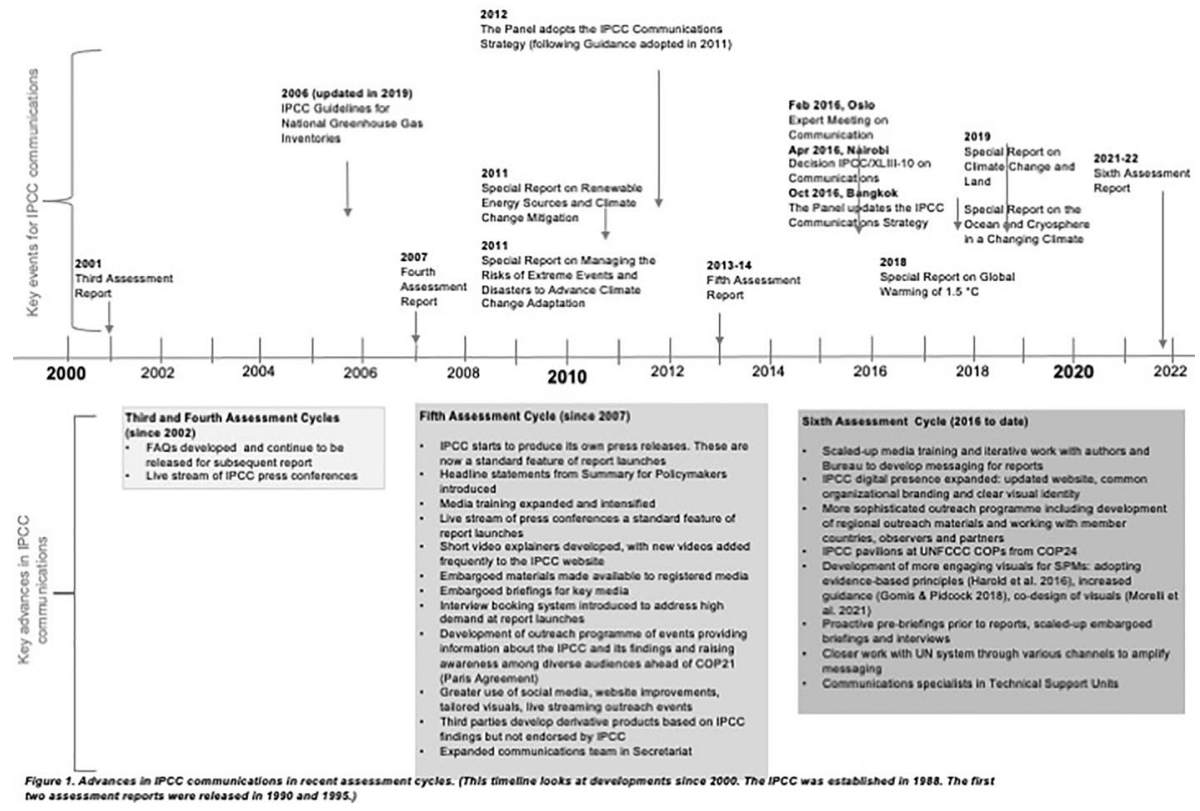

Fig 1. Advances in IPCC communications in recent assessment cycles. (This timeline looks at developments since 2000. The IPCC was established in 1988. The first two assessment reports were released in 1990 and 1995.)

in the specialist chapters. To support the creation of more accessible Summary for Policymaker figures, evidence-based principles about how people process and understand data visualizations (Harold et al. 2016) have been embedded throughout the drafting of recent reports, for example, by providing guidance to authors (Gomis and Pidcock 2018), holding figure workshops during author meetings, and reviewing draft figures in the context of cognitive science principles. In addition, interviews and surveys with users of reports have led to an improved understanding of how past summary for policymakers figures are used, and how draft figures are comprehended, further strengthening the design process (Fig. 1).

Another important tool is the Frequently Asked Questions, first introduced in the 2007 Fourth Assessment Report. By definition, these address issues of interest to the media and broader public. They allow IPCC authors and the scientific leadership to discuss questions in accessible language that has also gone through the formal IPCC review process. The Frequently Asked Questions have the potential to play a bigger role in presenting the main Sixth Assessment Report at its release and in subsequent outreach (see separate article in this Special Issue, Connors et al.). The Technical Summary, prepared by the authors alone, and with additional materials such as boxes on particular topics, is another valuable resource for media.

These various strands of work come together in a more professional approach to report releases. For instance the communications materials prepared for the Working Group I contribution to the Sixth Assessment Report prompted comments from media welcoming 
their clarity and usability, and the extensive programme of interviews and briefings before and after the release of the report led to record coverage. Early planning and strategic thinking for the report launches with a proactive media strategy have increased the visibility of the reports, a process that had already started during the Fifth Assessment cycle. All reports are released at a live-streamed press conference attended by hundreds of journalists in person and virtually. ${ }^{3}$ This is followed by interviews on demand with authors and Bureau members. Embargoed materials are provided prior to the event to accredited media to help them prepare their coverage. Proactive, prompt, and professional media relations go beyond the report release as part of the key activities of the IPCC communications team. This includes also keeping up with current trends, being open to new modes of communications, and measuring the media impact on a daily and monthly basis. Before the approval plenary and release of the report, groups of journalists receive briefings on the main topics that will be covered (without speculating on the final findings) and the factual background, such as numbers of authors and review comments. Reporters preparing more detailed advance articles on the report are put in contact with authors to help them explore and understand the key issues in more depth.

The IPCC website is the main showcase for IPCC products and information about the organization. During this cycle, the IPCC has put a greater emphasis on its digital presence with a new user-friendly and modern looking website and a common organizational branding and visual identity. Given its mandate, the IPCC cannot engage in conversations in social media (although it can provide clarifications), but since the Fifth Assessment Report, it has made much greater use of videos and social media, for instance linking to Frequently Asked Questions and past findings, particularly when the topic is in the news. Short video trailers or teasers can both launch a report presentation and serve as social media assets, while longer videos contribute to engaging outreach activities and report presentations and provide resources accessible through the website. This work has seen further improvements during the current cycle with in house, updated branding for social media and measuring the quantitative and qualitative impacts of communications work.

While some audiences use IPCC products directly, others use them to reach out to various stakeholders and develop tailored derivative products. These are based on the IPCC findings but not formally endorsed by the IPCC as they have not been prepared according to IPCC processes. Such "derivative products" may benefit from the involvement of IPCC experts in their development to ensure their accuracy, providing the IPCC with a further platform to raise awareness of its work. The bodies formally responsible for producing them have greater leeway in their use of accessible language than the IPCC itself does. One example from many would be the Summary for Teachers of the Special Report on Global Warming of $1.5^{\circ} \mathrm{C}$ prepared by the Office for Climate Education.

In strengthening the communications capacity and effectiveness of the IPCC, one priority has been to consider how the IPCC can work more effectively with external agents such as research institutions, NGOs, and media to strengthen their own communications. The IPCC's biggest asset is the hundreds of authors around the world contributing voluntarily to its work and providing its external face to the world. There is scope to draw on them even more to present the IPCC's work. Media training for authors underpins this as well as generating the messaging as described above. Where possible, the IPCC communications team organizes rehearsals for presentations, speeches, and events. The team support its speakers with speeches, presentations, and messaging. Since the Fifth Assessment Report cycle, dedicated presentations for each report have been prepared. During the Sixth Assessment Report cycle, the IPCC is stepping up efforts to develop targeted materials for various

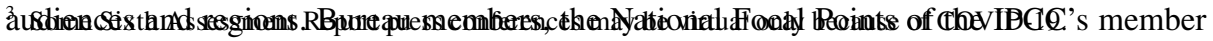


governments, and the IPCC's 174 observer organizations also provide powerful networks that can be drawn on for communications.

To support this demand for climate change information, the IPCC has held hundreds of outreach events around the world in the past years to present the role, activities, and findings of the IPCC in person and virtually. Each event is held in cooperation with a host institution to provide a local and regional perspective and tailored to the needs of the various audiences with specialized workshops and dedicated press conferences. Bilateral meetings with high-level state officials, presentations to parliamentarians, and city officials also take place. The IPCC is making an increasing effort through its communications and outreach activities to be more inclusive by engaging with both developing and developed countries and to broaden its traditional audiences to include, e.g., educators, youth, faith groups, city planners, and the business sector. This effort has helped bring in experts from previously underrepresented regions to participate in the work of the IPCC, such as author nominations, expert reviews, and new interest in joining as an observer organization.

In this cycle, the IPCC has had pavilions for the first time at the United Nations Climate Conferences (COPs 24, 25 and 26). These provide a high-profile hub for events, interviews, bilaterals, and other meetings with dedicated staff and experts to discuss the IPCC and climate change science. IPCC spokespeople contribute with scientific knowledge to various other major international, regional, and intergovernmental processes.

While IPCC reports are prepared in English, the IPCC also organizes and publishes translations of the Summary for Policymakers and the Technical Summary, as well as the press release announcing the report, into the other official U.N. languages (Arabic, Chinese, French, Russian, and Spanish). Organizations in countries with other languages may also organize non-official translations. Examples for the Special Report on Global Warming of $1.5^{\circ} \mathrm{C}$ can be found here (scroll down). Increasingly, materials for outreach events are also prepared in languages other than English.

\section{Summary}

The communications innovations in Sixth Assessment Report, building on those in the Fifth Assessment Report, appear to be bearing fruit. The first product in the Sixth assessment cycle, the 2018 Special Report on Global Warming of $1.5^{\circ} \mathrm{C}$, was one of the most influential reports on climate change ever, attracting enormous interest and transforming and galvanizing public interest in global warming. The two Special Reports that followed, Climate Change and Land and The Ocean and Cryosphere in a Changing Climate, have brought further interest in the work of the IPCC. This has focused greater attention and scrutiny on the IPCC. The public is more aware than previously of climate change and eager for information about it. Users of the report will be looking at the extent to which conclusions build on and are consistent with previous assessments, or whether they add dramatically new findings. Are the reports consistent across working groups? Do they lay out actionable solutions - in other words are they policy-relevant? And to what extent of the COVID-19 pandemic has led the IPCC is prepare the reports in virtual meetings? All this will put new demands on the IPCC to communicate effectively in the knowledge the findings of the IPCC are for everyone, everywhere. 


\section{Innovations in IPCC communications}

Fifth Assessment Report 2008-2015.

- IPCC Communications Strategy

- Second and third communications specialist in IPCC Secretariat

- Rapid response protocol

- Crisis communications expert on standby

- Protocol for handling leaks

- Press releases

- Headline statements

- Cooperation with makers of derivative products

- Media training

- Advance media briefings ahead of report releases

- Embargoed materials for report releases

- Embargoed interviews for report releases

- Live-streamed press conferences

- Satellite trucks and broadcast studios for interviews for report releases

- Systematic on-site and remote interview scheduling for report releases

- IPCC report videos

- Global outreach programme

Sixth Assessment Report 2015-present.

- Expert Meeting on Communication

- Website upgrade

- Communications specialists in Technical Support Units

- Fourth communications specialist in IPCC Secretariat

- Cooperation with communications scientists on presentation, text, and figures

- Messaging for reports from media training

- Continuing intensive outreach programme (virtual during pandemic)

- Leveraging outreach activities to encourage participation in IPCC process

- Enhanced social media and in-house video production

- Scripted rehearsed press conferences

- Pavilion at UN Climate Conference (COPs)

- Interactive figures and infographics

- Development of regionally specific materials

Author contribution J Lynn and N Peeva contributed equally to the writing of this manuscript.

Availability of data and materials Not applicable.

\section{Declarations}

Ethical approval Not applicable.

Consent to participate Yes, we both consent. 
Consent to publish Yes, we both consent.

Competing interests The authors declare no competing interests.

\section{References}

Corner A, Shaw C, Clarke J (2018) Principles for effective communication and public engagement on climate change: A Handbook for IPCC authors Climate Outreach Oxford

IPCC (2013) Climate Change 2013: The Physical Science Basis. Contribution of Working Group I to the Fifth Assessment Report of the Intergovernmental Panel on Climate Change [Stocker, T.F., D. Qin, G.-K. Plattner, M. Tignor, S.K. Allen, J. Boschung, A. Nauels, Y. Xia, V. Bex and P.M. Midgley (eds.)]. Cambridge University Press, Cambridge, 1535 pp

IPCC (2014) Climate Change 2014: Synthesis Report. Contribution of Working Groups I, II and III to the Fifth Assessment Report of the Intergovernmental Panel on Climate Change [Core Writing Team, R.K. Pachauri and L.A. Meyer (eds.)]. IPCC, Geneva, $151 \mathrm{pp}$

IPCC (2018) Summary for Policymakers. In: Global Warming of $1.5^{\circ} \mathrm{C}$. An IPCC Special Report on the impacts of global warming of $1.5^{\circ} \mathrm{C}$ above pre-industrial levels and related global greenhouse gas emission pathways, in the context of strengthening the global response to the threat of climate change, sustainable development, and efforts to eradicate poverty [Masson-Delmotte, V., P. Zhai, H.-O. Pörtner, D. Roberts, J. Skea, P.R. Shukla, A. Pirani, W. Moufouma-Okia, C. Péan, R. Pidcock, S. Connors, J.B.R. Matthews, Y. Chen, X. Zhou, M.I. Gomis, E. Lonnoy, T. Maycock, M. Tignor, and T. Waterfield (eds.)]. World Meteorological Organization, Geneva, Switzerland, $32 \mathrm{pp}$

IPCC (2016) Meeting Report of the Intergovernmental Panel on Climate Change Expert Meeting on Communication [Lynn, J., M. Araya, Ø. Christophersen, I. El Gizouli, S.J. Hassol, E.M. Konstantinidis, K.J. Mach, L.A. Meyer, K. Tanabe, M. Tignor, R. Tshikalanke, J.-P. van Ypersele (eds.)]. World Meteorological Organization, Geneva, Switzerland, $229 \mathrm{pp}$

Gomis, M. I. \& Pidcock, R. (2018). IPCC visual style guide for authors. Published by IPCC WGI Technical Support Unit. https://www.ipcc.ch/site/assets/uploads/2019/04/IPCC-visual-style-guide.pdf

Harold J, Lorenzoni I, Shipley TF, Coventry KR (2016) Cognitive and psychological science insights to improve climate change data visualization. Nat Clim Chang 6(12):1080-1089

Publisher's Note Springer Nature remains neutral with regard to jurisdictional claims in published maps and institutional affiliations. 